\title{
Proapoptotic Bid mediates the Atr-directed DNA damage response to replicative stress
}

\author{
Y Liu', CC Bertram ${ }^{1}, Q$ Shi $^{2}$ and SS Zinkel ${ }^{*, 1,2}$
}

Proapoptotic BH3 interacting domain death agonist (Bid), a BH3-only Bcl-2 family member, is situated at the interface between the DNA damage response and apoptosis, with roles in death receptor-induced apoptosis as well as cell cycle checkpoints following DNA damage. ${ }^{1-3}$ In this study, we demonstrate that Bid functions at the level of the sensor complex in the Atm and Rad3-related (Atr)-directed DNA damage response. Bid is found with replication protein A (RPA) in nuclear foci and associates with the Atr/Atr-interacting protein (Atrip)/RPA complex following replicative stress. Furthermore, Bid-deficient cells show an impaired response to replicative stress manifest by reduced accumulation of Atr and Atrip on chromatin and at DNA damage foci, reduced recovery of DNA synthesis following replicative stress, and decreased checkpoint kinase 1 activation and RPA phosphorylation. These results establish a direct role for the BH3-only Bcl-2 family member, Bid, acting at the level of the damage sensor complex to amplify the Atr-directed cellular response to replicative DNA damage.

Cell Death and Differentiation (2011) 18, 841-852; doi:10.1038/cdd.2010.151; published online 26 November 2010

The Bcl-2 family of proteins regulates the intrinsic pathway of programmed cell death or apoptosis. The BH3-only members of the family function as sensors, relaying death signals to the core apoptotic machinery at the mitochondria. $\mathrm{BH} 3-$ only $\mathrm{BH} 3-$ interacting domain death agonist (Bid) has a unique function in apoptosis to interconnect the death receptors of the extrinsic pathway to the mitochondrial amplification loop of the intrinsic pathway. ${ }^{4,5}$ Despite the potent role of Bid in apoptosis, Bid-deficient mice develop normally, but show deregulated myeloid homeostasis, culminating in a clonal disorder closely resembling human chronic myelomonocytic leukemia $(\mathrm{CMML}){ }^{6}$ Bid-deficient myeloid progenitor cells (MPCs) show an increased mitomycin c-induced chromosomal breaks, ${ }^{2}$ and Bid-deficient leukemias show chromosomal abnormalities. ${ }^{6}$ Following DNA damage, Atm, and/or Atm and Rad3-related (Atr) phosphorylate Bid on Ser61/64 and Ser78, and this phosphorylation is required for proper regulation of $S$ phase after DNA damage. ${ }^{1,2,7}$ Thus, Bid has two distinct and separable functions in apoptosis and the DNA damage response.

A highly regulated response program senses and repairs DNA damage. ${ }^{8}$ Two phosphoinositide 3-kinase-related protein kinases (PIKKs), Atm, and Atr, sense DNA damage at the site of the DNA lesion and activate downstream transducers to engage the checkpoint and DNA repair machinery, ${ }^{8}$ or the apoptotic pathway. ${ }^{10}$ Atm responds primarily to double strand breaks, and Atr to replication protein A (RPA)-coated singlestranded DNA (ssDNA) by interaction with its stable binding partner Atr/Atr-interacting protein (Atrip). ${ }^{9-11}$
Stalled replication forks created by replicative stress produce a distinct DNA lesion comprised of RPA-coated ssDNA adjacent to a stretch of dsDNA. RPA recruits a multiprotein complex at the site of the DNA lesion, comprised of Atrip, interacting with RPA via its checkpoint recruitment domain (CRD) and its stable binding partner Atr. ${ }^{12}$ Rad17 independently recruits the Rad9-Hus1-Rad1 complex (9-1-1 complex) to stalled replication forks. ${ }^{13,14}$ The $9-1-1$ complex then recruits topoisomerase-binding protein 1 (TopBP1), ${ }^{15}$ to associate with Atrip and Atr, and stimulate Atr kinase activity. ${ }^{16}$ Activated Atr phosphorylates a multitude of downstream effectors to initiate the complex cellular response to replicative stress, including activation of checkpoints, DNA repair, and apoptosis.

Proapoptotic Bid functions in apoptosis as well as the DNA damage response. ${ }^{1-3}$ Two independent groups have demonstrated that Bid is found in the nucleus after DNA damage, is phosphorylated by Atm and/or Atr, and mediates efficient activation of an S-phase checkpoint. ${ }^{1,2,17}$ Bid has also been identified in a screen of proteins phosphorylated in response to DNA damage on consensus Atm/Atr phosphorylation sites. ${ }^{7}$ Furthermore, mice expressing mutated Nijmegen breakage syndrome 1 demonstrate defective Atm activation and Bid phosphorylation. ${ }^{18}$ Nonetheless, the mechanism by which Bid interacts within the DNA damage response is unknown, and there is some controversy in the literature, primarily concerning the generality of role of Bid in DNA damage-induced apoptosis. ${ }^{19}$ Of note, transient knockdown (KD) of Bid was not tested in the above studies, therefore, the

\footnotetext{
${ }^{1}$ Department of Cell and Developmental Biology, Vanderbilt University School of Medicine, Nashville, TN, USA and ${ }^{2}$ Department of Medicine, Vanderbilt University School of Medicine, Nashville, TN, USA

${ }^{*}$ Corresponding author: SS Zinkel, Department of Medicine, Vanderbilt University School of Medicine, 548 PRB, Nashville, TN 37232, USA. Tel: +615 936 1801; Fax: + 615936 3853; E-mail: Sandra.zinkel@ vanderbilt.edu

Keywords: Bid; DNA damage; Atr; Atrip

Abbreviations: Atm, ataxia telangiectasia mutated; Atr, Atm and Rad3-related; Bid, BH3-interacting domain death agonist; Chk1, checkpoint kinase 1; CMML, chronic myelomonocytic leukemia; ETOP, etoposide; HU, hydroxyurea; IP, immunoprecipitation; KD, knockdown; MPCs, myeloid progenitor cells; PIKKs, phosphoinositide 3-kinase-related protein kinases; RPA, replication protein A; ssDNA, single-stranded DNA; TopBP1, topoisomerase-binding protein 1

Received 09.8.10; revised 13.10.10; accepted 14.10.10; Edited by JM Hardwick; published online 26.11.10
} 
differences may have been attributable to compensation of cells to the absence of Bid in a given experimental setting. Indeed, a recent report ${ }^{20}$ showed defects in $S$ phase following replicative stress induced by thymidine in Bid KD HCT116 cells.

In this study, we demonstrate that Bid facilitates Atr signaling, acting at the DNA damage sensor complex in response to replicative stress. In the absence of Bid, Atr function is limited, as measured by recruitment of Atr and Atrip to chromatin and nuclear foci following hydroxyurea $(\mathrm{HU})$, phosphorylation of Atr substrates, and recovery of DNA replication following replicative stress (stalled replication forks). In addition, Bid is found in nuclear foci with RPA following $\mathrm{HU}$-induced replicative stress, and associates with members of the DNA damage sensor complex, Atr, Atrip, and RPA. Importantly, the Atr/Atrip association with RPA is diminished in the absence of Bid. Furthermore, Bid's Atrip association is required for checkpoint kinase 1 (Chk1) phosphorylation and accumulation of Atrip at nuclear foci following $\mathrm{HU}$. Thus, we demonstrate that Bid facilitates the response of the Atr-mediated pathway to replicative stress through association with Atrip at DNA damage foci, functioning at the level of the sensor complex.

\section{Results}

Bid is expressed in tissues with proliferating cells. Our previous results show increased chromosomal damage and increased sensitivity of Bid-deficient MPCs after treatment with agents inducing replicative stress. ${ }^{2,6,17}$ Bid is highly expressed in tissues that contain proliferating cells, such as thymus, bone marrow, and spleen, as well as intestinal epithelium after DNA damage, ${ }^{21}$ but not in tissues comprised primarily of post-mitotic cells, such as brain and lungs (Figure 1a). In addition, the expression level of Bid correlates with that of PCNA, a marker for cell proliferation (Figure 1a). Bid is, therefore, expressed in settings, in which cells are undergoing proliferation.

Bid-/- bone marrow cells are more sensitive to replicative stress. We asked whether Bid might have a role in vivo to monitor the response to replicative stress by treating mice with $\mathrm{HU}$, a ribonucleotide reductase inhibitor that predominantly triggers activation of the Atr-mediated signaling pathway. Hematopoietic progenitor cells proliferate and repopulate the bone marrow following insult, and are vulnerable to agents inducing replicative stress. Bid-/- but not $\mathrm{Bid}+/+$ bone marrow cells are more sensitive to systemic treatment with $100 \mathrm{mg} / \mathrm{kg} \mathrm{HU}$ in vivo (Figure $1 \mathrm{~b}$ ), but not to a low dose of infrared radiation (2Gy), suggesting specific sensitivity to replicative stress. We, thus, demonstrate that Bid has a role in vivo to mediate the response of bone marrow to $\mathrm{HU}$-induced replicative stress.

\section{Bid has a role in recovery and completion of DNA} replication following $\mathrm{HU}$. One function of activated Atr that is distinct to Atr among the PIKKs is to facilitate cell cycle re-entry after the release of replicative stress. ${ }^{22}$ U2OS cells transfected with siRNA directed against Bid (Bid KD) or a control siRNA (control KD) were arrested in early S phase by $10 \mathrm{mM} \mathrm{HU}$ for $24 \mathrm{~h}$. HU was washed out and cells were released into fresh medium with nocodazole to prevent cell division. Asynchronous Bid KD and control KD U2OS cells showed similar cell cycle profiles at baseline (Figures 1c and d). Bid KD but not control KD U2OS cells demonstrated impaired DNA replication recovery and impaired progression through S phase (Figure 1c, Supplementary Figure S1A), but no significant increase in apoptotic cells as measured by $<2 N$ DNA content (Supplementary Figure S1B). Thus, the recovery of DNA replication and completion of $S$ phase after replicative stress was significantly impaired in the absence of Bid further suggesting a defect in Atr activation in the absence of Bid.

Bid does not mediate TopBP1-directed Atr activation in vitro. To determine whether Bid modulates TopBP1 activation of Atr, Atr-Atrip was purified by immunoprecipitation (IP) from 293T cells, and incubated with purified TopBP1 AAD, $\gamma_{-}{ }^{32}$ P-ATP, and Mcm2 as an Atr substrate, ${ }^{12}$ with and without Bid (Supplementary Figure S2A). Atr-Atrip phosphorylated Bid and Mcm2, however, the presence of Bid did not alter Mcm2 phosphorylation. Bid is, thus, a substrate of Atr but does not modulate TopBP1-directed Atr activation in this in vitro system.

Bid has a role in recruitment or maintenance of Atrip to nuclear foci following replicative stress. In the presence of replicative stress, Atrip and Atr are recruited to stalled replication forks and accumulate in nuclear foci. Bid-deficient cells demonstrated decreased Atr/Atrip accumulation in chromatin following $\mathrm{HU}$ relative to $\mathrm{Bid}+/+$ cells (Figure 1e). Bid KD U2OS cells demonstrate decreased accumulation of Atrip in HU-induced DNA damage foci (Figures $1 \mathrm{f}$ and $\mathrm{g}$ ). Importantly, reintroducing wild-type Bid into Bid KD U2OS cells restored Atrip accumulation at nuclear foci (Figures $1 \mathrm{f}$ and $\mathrm{g}$ ). No HU-induced increase in Atr or Atrip levels was seen in control U2OS cells; a modest $\mathrm{HU}$-induced increase in Atr protein level was observed following DNA damage in Bid $+/+$ but not Bid-/- MPCs (Supplementary Figure S2B and $\mathrm{C}$ ). The above data are consistent with a role for Bid in recruitment or maintenance of Atr and Atrip at nuclear foci following DNA damage.

Apoptosis activates DNAases. To rule out Bid-induced apoptosis as the etiology of Atrip accumulation at nuclear foci, we evaluated caspase 3 activation by immunofluorescence following reintroduction of Bid (Supplementary Figure S2D and E). Death receptor stimulation but not HU treatment activates caspase 3 in U2OS cells. Reintroduction of $\mathrm{Bid}+/+$ to $\mathrm{Bid} \mathrm{KD}$ U2OS cells treated with $\mathrm{HU}$ does not activate caspase 3 , indicating that the Atrip accumulation at nuclear foci is not due to Bid-induced apoptosis.

DNA damage-induced phosphorylation of Atr substrates is diminished in the absence of Bid. We next evaluated phosphorylation of the Atr effectors, Chk1 and RPA32. Following $\mathrm{HU}$ treatment, Chk1 immunoblot displayed phosphatase-sensitive slower migrating bands that reacted with antibodies specific for phospho-Chk1 (S317) and (S345; 


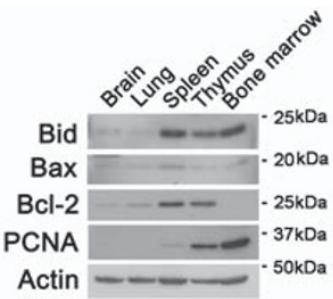

b

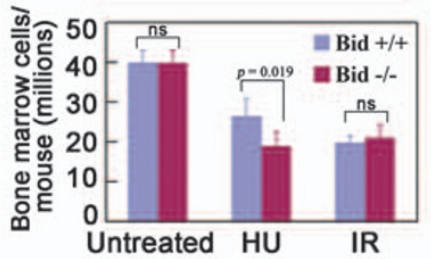

C

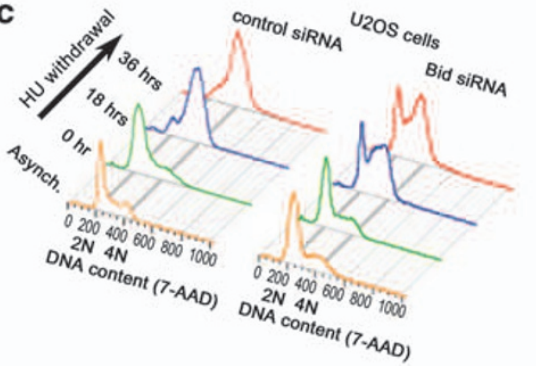

d

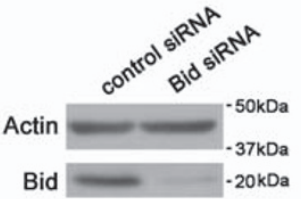

e
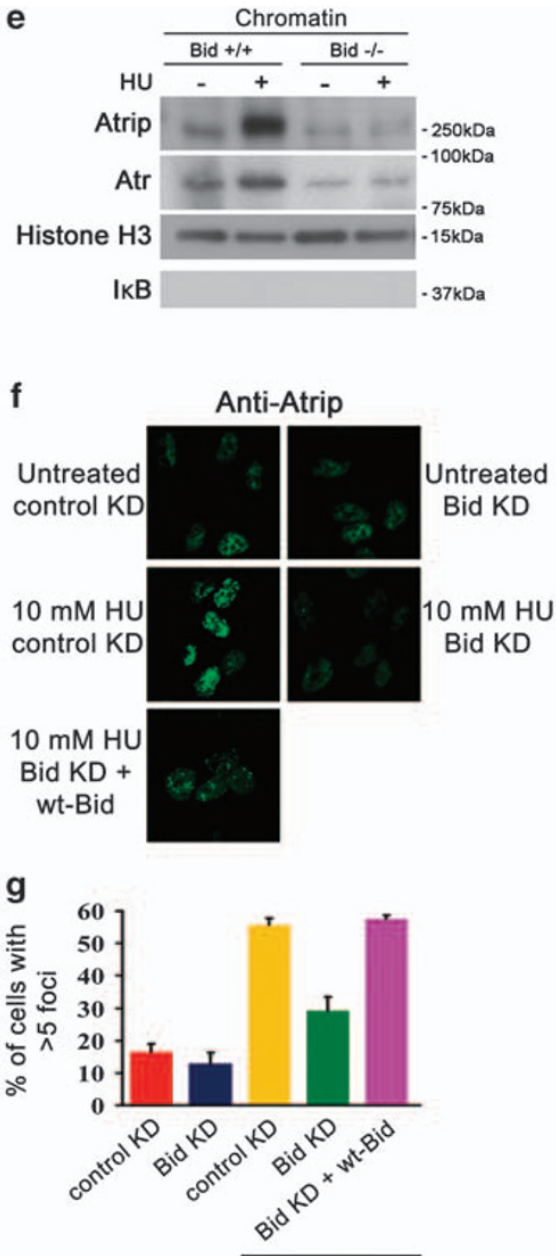

HU

Figure 1 The cellular recovery from replicative stress and the HU-induced accumulation of Atrip at nuclear foci are impaired in the absence of Bid. (a) Bid is highly expressed in hematopoietic tissues. Tissues were harvested from wild-type C57BI6 mice. Total cell lysates from the indicated tissues were resolved by SDS-PAGE and immunoblotted with the indicated antibodies. The molecular weight markers used in immunoblots are labeled on the right of the blots. (b) Bid $-/-$ bone marrow cells are more sensitive to replicative stress. Bid $+/+$ and Bid-/- mice were injected with $100 \mathrm{mg} / \mathrm{kg}$ hydroxyurea $(\mathrm{HU})$ for 3 consecutive days. Mice were killed and bone marrow was harvested from mouse femurs and tibia at $24 \mathrm{~h}$ after the third injection. Bid $+/+$ and Bid $-/-$ mice were irradiated with $2 \mathrm{~Gy}$ using a ${ }^{137} \mathrm{Cs}$ source. Mice were killed and bone marrow was harvested from mouse femurs and tibia $24 \mathrm{~h}$ after irradiation. Following lysis of red blood cells, viable bone marrow cells were identified by trypan blue exclusion and counted. $N=15$ mice for $\mathrm{HU}$ treatment and $n=10$ mice for irradiation treatment. Error bar $=90 \%$ confidence interval. $P$-value is calculated by student's $t$-test. (c) U2OS cells were transfected with control siRNA or Bid siRNA. After 2 days, cells were exposed to $10 \mathrm{mM} \mathrm{HU}$ for $24 \mathrm{~h}$, and released into fresh media containing $1 \mu \mathrm{g} / \mathrm{ml}$ nocodazole for the indicated times. Cells were fixed and stained with 7-AAD and analyzed by flow cytometry. (d) U2OS cells were transfected with control siRNA or Bid siRNA for $72 \mathrm{~h}$. Cells were lysed and Bid was detected in immunoblots. (e) Bid $+/+$ and Bid - / MPCs were treated with $10 \mathrm{mM}$ HU for $2 \mathrm{~h}$. The chromatin fraction was isolated and extracts were resolved on SDS-PAGE and immunoblotted with the indicated antibodies. (f) U2OS cells were transfected with control siRNA or Bid siRNA and wild-type mouse Bid was introduced into the cells simultaneously with siRNA. Cells were treated with $10 \mathrm{mM} \mathrm{HU}$ for $5 \mathrm{~h}$, fixed, and stained with anti-Atrip antibody. Representative images of Atrip staining were shown. (g) Quantitative analysis of Atrip accumulation at nuclear foci following replicative stress. The percentage of cells with $>5$ clearly visible Atrip nuclear foci was calculated for each cell type. More than 600 cells were counted in three independent experiments

Figures $2 a$ and b, Supplementary Figure S3A). These bands were diminished in Bid-/- MPCs following HU treatment (Figures $2 \mathrm{a}$ and $\mathrm{b}$ ). To acutely decrease Bid protein levels, siRNAs targeted against human Bid and mouse Bid mRNA were introduced into human U2OS cells and mouse MPCs, respectively, decreasing Bid levels to $<20 \%$ of endogenous levels in U2OS cells using siRNA7, and nearly completely using siRNA8 (Figure 2c). Bid-deficient U2OS cells (Figure 2c) and MPCs (Figures 2a and b, Supplementary Figure S3B and D) displayed diminished phosphorylated Chk1 following $\mathrm{HU}$ or etoposide (ETOP) treatment.
Furthermore, the degree of decreased Chk1 phosphorylation correlated with the degree of Bid KD. Interestingly, the Chk1 level is increased in Bid-/- MPCs (Figures $2 a$ and b), but not in U2OS cells when Bid was knocked down by siRNA (Figure 2c), consistent with a compensatory increase in Chk1 levels in the setting of chronic absence of Bid, but not when Bid is lost acutely. These results implicate Bid in mediating Atr function.

We next evaluated effectors of the DNA damage response, such as Cdc25a in Bid $+/+$ and Bid-/- cells. Cdc25a is phosphorylated by Chk1 following replicative stress, targeting 
a

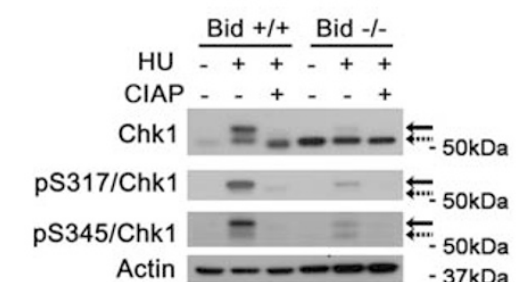

b

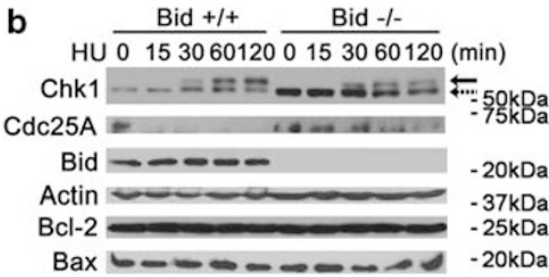

c

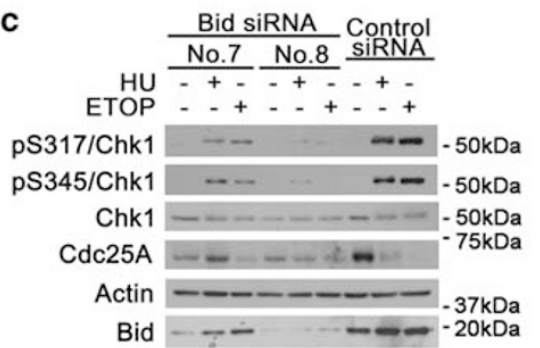

d

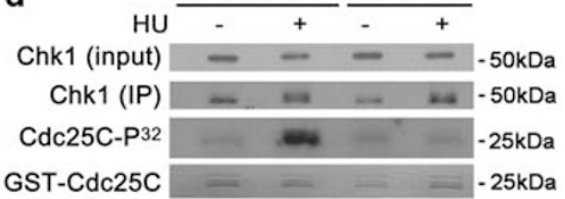

e

e

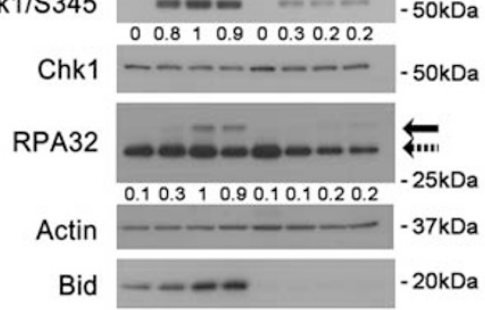

Figure 2 The phosphorylation of Atr substrates are diminished in Bid-deficient cells following replicative stress. (a) Phosphorylated mouse Chk1 presents as a shifted band. Bid $+/+$ and Bid-/- MPCs were treated with $10 \mathrm{mM} \mathrm{HU}$ for $2 \mathrm{~h}$. Whole-cell extracts were incubated with $10 \mathrm{U}$ Calf Intestinal Alkaline Phosphatase (Invitrogen)/ $100 \mu \mathrm{g}$ lysate, resolved by SDS-PAGE and immunoblotted with anti-Chk1, anti-pChk1 (S317), or anti-pChk1 (S345) as indicated. Solid arrows denote the mobility of shifted phosphorylated Chk1, and dashed arrows denote the mobility of unphosphorylated Chk1. (b) Bid + I+ and Bid-/ - MPCs were treated $10 \mathrm{mM} \mathrm{HU}$ for the indicated times. Total cell lysate was resolved by SDS-PAGE followed by immunoblotting with the indicated antibodies. (c) U2OS cells were treated with Bid-specific siRNA no.7, Bid-specific siRNA no.8, or control siRNA for $72 \mathrm{~h}$. Bid KD and control KD cells were treated with $10 \mathrm{mM} \mathrm{HU}$ or $25 \mu \mathrm{M} \mathrm{ETOP}$ for $2 \mathrm{~h}$, and total cell lysate was resolved by SDS-PAGE followed by immunoblotting with the indicated antibodies. (d) U2OS cells transfected with control siRNA or Bid siRNA (no. 8) for $72 \mathrm{~h}$ were treated with $10 \mathrm{mM} \mathrm{HU}$ for $2 \mathrm{~h}$. Whole-cell lysates were immunoprecipitated with anti-Chk1 antibody, and the immunoprecipitated product was incubated with $1 \mu \mathrm{g}$ GST-Cdc25C protein, $10 \mu \mathrm{M}$ cold ATP and $5 \mu \mathrm{Ci} \gamma_{-}{ }^{32} \mathrm{P}$-ATP in kinase buffer. Chk1 kinase reactions were resolved on SDS-PAGE, stained with SimplyBlue SafeStain (Invitrogen) to visualize GST-cdc25c levels, and analyzed by autoradiography. (e) Bid + I + and Bid-/- MPCs were treated $10 \mathrm{mM} \mathrm{HU}$ over time. Total cell lysate was resolved by SDS-PAGE followed by immunoblot with the indicated antibodies. Relative band intensity has been measured by densitometry analysis. (f) U2OS cells were transfected with control siRNA or Bid siRNA for $72 \mathrm{~h}$, and then treated with $10 \mathrm{mM} \mathrm{HU}$ over time. Total cell lysate was resolved by SDS-PAGE followed by immunoblot with the indicated antibodies. Solid arrow denotes the mobility of shifted phosphorylated RPA32, and dashed arrow denotes the mobility of unphosphorylated RPA32. Relative band intensity was measured by densitometry analysis

it for degradation. ${ }^{23,24}$ Cdc25a degradation following DNA damage was delayed in Bid-/- MPCs as well as in Bid KD U2OS cells (Figures $2 \mathrm{~b}$ and c, Supplementary Figure S3B. Interestingly, Cdc25a levels are increased in untreated Bid-/- MPCs but not in Bid KD U2OS cells, consistent with a compensatory increase in Cdc25a levels in the setting of prolonged loss of Bid. These results implicate Bid in mediating Chk1 function.

We further evaluated Chk1 kinase activity via IP of Chk1 from control siRNA and Bid siRNA-transfected U2OS cells followed by incubation with GST-cdc25C and $\gamma^{32}$ P-ATP. The anti-Chk1 antibody immunoprecipitated both Chk1 and phosphorylated Chk1 (Supplementary Figure S3E and F). Following HU treatment, Bid KD U2OS cells demonstrated decreased kinase activity relative to control KD cells suggesting that the $\mathrm{HU}$-induced Chk1 activity, or a kinase associated with Chk1, is decreased in the absence of Bid
(Figure 2d). These results strongly suggest that $\mathrm{HU}$-induced Chk1 activation is decreased in the absence of Bid.

We next evaluated phosphorylation of the Atr targets p53 and RPA32 following replicative stress. p53 phosphorylation at Ser15 (Figure 2E, Supplementary Figure S4A), and the HUinduced expression levels of the p53 target genes p21 and Noxa $^{25}$ were diminished (Supplementary Figure S4B) in Bid-/- MPCs following HU treatment. Furthermore, RPA32 phosphorylation was decreased in Bid-/- MPCs (Figure 2e) and in U2OS cells upon siRNA KD of Bid (Figure 2f). Thus, in the absence of Bid, phosphorylation of multiple Atr substrates was diminished, consistent with a role for Bid in Atr activation.

In contrast, the autophosphorylation of Atm was normal in the absence of Bid following ETOP treatment in U2OS cells (Supplementary Figure S4C), suggesting that Bid does not has a major role in Atm activation. In addition, Chk1 phosphorylation was diminished in Bid/Atm-deficient U2OS 
a

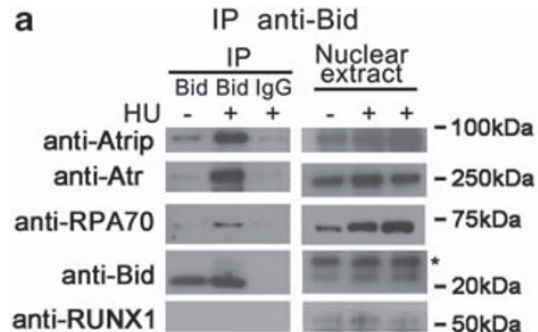

e

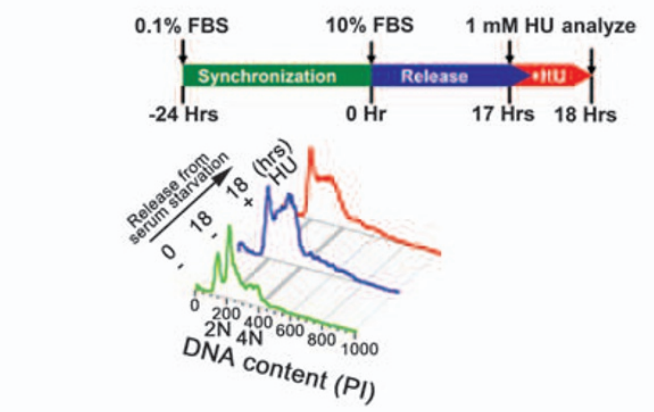

b

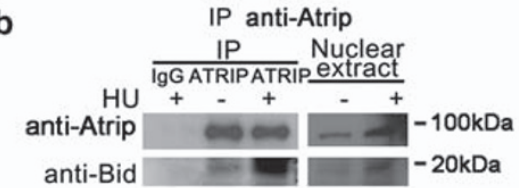

C
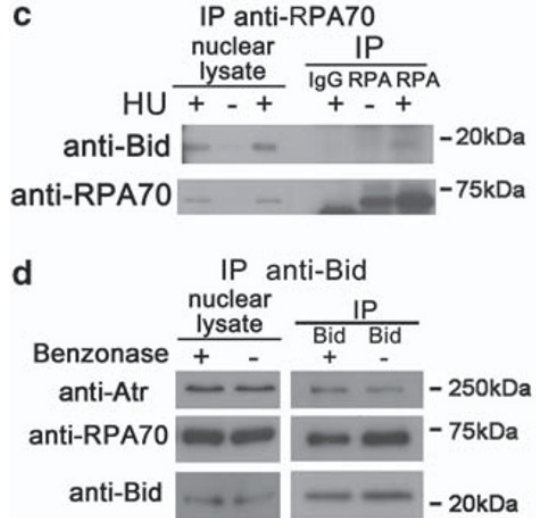

f
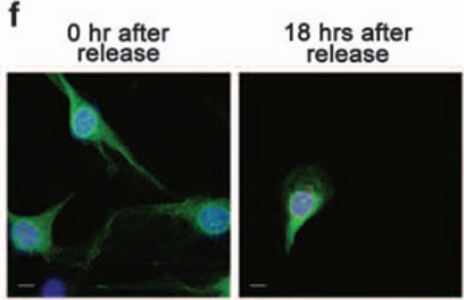

$18 \mathrm{hrs}$ after release
$+\mathrm{HU}$
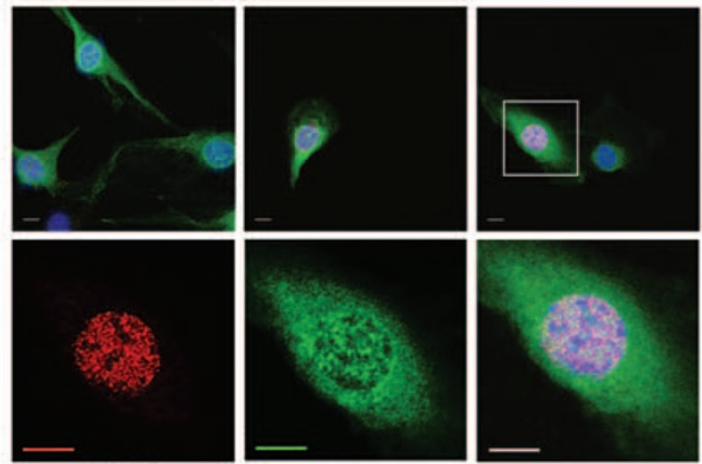

Bid

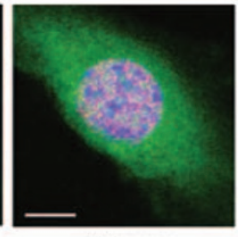

Merge

Figure 3 Bid associates and co-localizes with Atr/Atrip/RPA complex following replicative stress. (a) Bid $+/+$ and Bid -/ - MPCs were treated with $10 \mathrm{mM} \mathrm{HU}$ for $2 \mathrm{~h}$. Bid was immunoprecipitated from nuclear extracts using biotin-conjugated anti-Bid antibody and streptavidin-agarose beads. Samples were analyzed using SDS-PAGE followed by immunoblotting with the indicated antibodies. The asterisk ( $\left(^{*}\right)$ indicates a crossreacting band. Transcription factor RUNX1 was used as a negative control. (b) U2OS cells were treated with $10 \mathrm{mM} \mathrm{HU}$ for $2 \mathrm{~h}$. Cells were harvested, and Atrip was immunoprecipitated from nuclear extracts using anti-Atrip (401) antibody. Immunoprecipitates were analyzed using SDS-PAGE followed by immunoblotting with anti-Bid and anti-Atrip antibodies. (c) U2OS cells were treated with $10 \mathrm{mM} \mathrm{HU}$ for $2 \mathrm{~h}$. Cells were harvested, and RPA was immunoprecipitated from nuclear extracts using anti-RPA70 antibody. Immunoprecipitates were resolved by SDS-PAGE followed by immunoblotting with anti-Bid and anti-RPA70 antibodies. (d) The interaction between Bid and Atr complex is independent of DNA. Bid +/+ MPCs were treated with $10 \mathrm{mM} \mathrm{HU}$ for $2 \mathrm{~h}$. Then, the nuclear fraction was purified and incubated with 250U Benzonase Nuclease (Novagen). Then, Bid was immunoprecipitated from nuclear extracts using biotin-conjugated anti-Bid antibody and streptavidin-agarose beads. Samples were analyzed using SDS-PAGE followed by immunoblotting with the indicated antibodies. (e) Bid-/- MEFs harboring HA-tagged Bid were synchronized in low serum medium (0.1\% FBS-DMEM) for $24 \mathrm{~h}$. Following synchronization, cells were released into complete medium (10\% FBS-DMEM). At $17 \mathrm{~h}$ after release, cells were left untreated ( $18 \mathrm{~h}$ serum) or treated for $1 \mathrm{~h}$ with $1 \mathrm{mM} \mathrm{HU}$ ( $18 \mathrm{~h}$ serum plus $\mathrm{HU}$ ). Then, cells were fixed and stained for anti-HA and anti-RPA32 antibodies. Representative images in (f) were captured by a Zeiss LSM 510 inverted confocal microscopy. Scale bars represent $10 \mu \mathrm{m}$

cells as well as Bid-deficient U2OS cells (Supplementary Figure S4D), suggesting that the function of Bid in the Atr-mediated response is independent of Atm.

Chk1 phosphorylation increases in S phase. We observed no significant difference in the percentage of cells in $S$ phase between $\mathrm{Bid}+/+$ and $\mathrm{Bid}-/-$ cells (Supplementary Figure S5A and B). To stringently evaluate the status of Chk1 phosphorylation at a defined stage of the cell cycle, we performed intra-cellular phospho-Chk1 staining with 7-AAD costaining followed by flow cytometry. Bid-/- cells showed decreased numbers of phospho-Chk1 ${ }^{+}$cells, and the mean fluorescence index of phospho-Chk1 staining was significantly decreased relative to Bid $+/+$ cells within the total cell population and in cells in late S/G2/M (Supplementary Figure S5D and $\mathrm{K}$ ), demonstrating on a per cell basis that phosphoChk1 is decreased in Bid-/- cells. Thus, the differences in Chk1 phosphorylation observed in Bid-deficient cells were not because of an alteration of the cell cycle profile. ${ }^{26-28}$
Bid associates with Atr/Atrip/RPA. The findings outlined above implicate a role for Bid very early in the DNA damage response, at the level of Atr activation and recruitment to DNA damage foci. We, therefore, examined the ability of Bid to associate with the DNA damage sensor complex, composed of Atr, Atrip, and RPA. ${ }^{9}$ Atr, Atrip, and RPA coimmunoprecipitated with Bid from nuclear extracts, and this co-IP was enhanced after HU treatment (Figure 3a). Mouse but not human Bid co-migrates with the immunoglobulin light chain on SDS-PAGE, therefore, we performed the reverse IP in U2OS cells. When endogenous Atrip or RPA was immunoprecipitated from the nuclear fraction of U2OS cells, Bid was detected in the immunoprecipitated product (Figures $3 b$ and $c$ ). Furthermore, when purified Bid was incubated with purified RPA complex, RPA complex immunoprecipitated with Bid (Supplementary Figure S6A). The anti-Bid antibody did not nonspecifically precipitate DNA as shown by immunoblotting with anti-Runx1 antibody. The above results are 
consistent with an association of Bid with the RPA complex at stalled replication forks following replicative stress.

The Bid/Atr/Atrip/RPA association does not require DNA. To determine whether the association of Bid with the RPA/Atr/Atrip complex requires DNA, we isolated nuclear extracts from HU-treated Bid $+/+$ and Bid-/- MPCs and incubated the extracts with DNAase. There is no change in the association of Bid with Atr or RPA70 following DNAase treatment (Figure $3 \mathrm{~d}$ ), indicating that the association of Bid with RPA/Atr/Atrip is not dependent on intact DNA.

Bid is found at nuclear foci with RPA following HU. The above results implicate a role for Bid at the site of DNA damage following replicative stress, at stalled replication forks. To determine whether Bid is present at these structures following DNA damage, we synchronized Bid-/MEFs stably expressing FlagHA-tagged Bid (FHABid MEFs) in $\mathrm{G} 1$ by incubation in reduced serum $(0.1 \% \mathrm{FBS})$ medium for $24 \mathrm{~h}$, then released the cells into complete medium $(10 \%$ FBS; (Figure 3e). The population of S-phase cells was enriched $17 \mathrm{~h}$ after release (Figure $3 \mathrm{e}$ ), whereupon cells were left untreated or treated with $1 \mathrm{mM} \mathrm{HU}$ for $1 \mathrm{~h}$. Immunofluorescence using antibodies to HA and RPA32 revealed the presence of Bid and RPA32 in nuclear foci in synchronized FHABid cells treated with $\mathrm{HU}$, but not in untreated cells, or serum-starved cells (Figure 3f, Supplementary Figure S6B). Bid is thus present in the region of stalled replication forks following $\mathrm{HU}$ treatment.

Bid helix 4 associates with Atrip. To determine the domain of Bid that associates with Atrip, various Bid mutants were transiently overexpressed in 293T cells with HA-tagged Atrip (Figure 4a). Cells that were untreated or treated with HU were harvested, and Bid was immunoprecipitated from total cell extracts. Interestingly, Bid mutants targeting the well-studied $\mathrm{BH} 3$ domain and phosphorylation sites still associated with Atrip (Figure 4b). Successive deletion of $\alpha$-helices beginning at the $C$ terminus of Bid revealed that the Bid-Atrip association was maintained and enhanced following DNA damage even in the absence of helices 5-8, but not helix 4 (data not shown). On the basis of nuclear magnetic resonance structure of Bid (Figure 4c), Leu105, Leu109, GIn112, and Asn115 in helix 4 are on the outer face of the protein, providing a candidate surface to interact with other proteins. ${ }^{29,30}$ Site-directed mutagenesis of Leu105 and Leu109 to polar cysteine residues (BidH4A), or mutation of Gln112 and Asn115 to alanine residues (BidH4B), severely diminished the Bid-Atrip association (Figures $4 a$ and $d$ ). Mutating residues in the loop between helices 4 and 5 by mutating Ser117 and Ser119 to alanines (loop A) or mutating Glu120, Glu121, and Asp122 to glycines (loop B) had a less severe effect (Figures 4a and d). Finally, we purified Escherichia coli-expressed Bid and His-MBPfused Atrip. Bid, but not BidH4A or BidH4B immunoprecipitated with full-length Atrip (Figure 4e). The above data indicate that Bid interacts with Atrip, and this interaction is dependent on an intact Bid helix 4. Of note, Bid helix 4 is highly conserved between human, mouse, and rat (Figure 4c), underscoring its potential importance, and raising the possibility that the function of Bid in the DNA damage signaling pathway might be a unique characteristic of Bid among Bcl-2 family members.

Bid binds to the Atrip coiled-coil domain. To determine the domain of Atrip required for the association with Bid, various HA-tagged Atrip mutants, ${ }^{31}$ were tested for Bid-Atrip association in 293T cells as above (Figures $4 \mathrm{f}$ and $\mathrm{i}$ ). Deletion of the first 107 amino acids of Atrip, including the CRD or amino acids 181-435 (TopBP1-binding domain) had no effect on the association of Bid with Atrip (Figure $4 \mathrm{~g}$ ). Deletion of amino acids 112-414 significantly decreased the Bid-Atrip association (Figures $4 \mathrm{~g}$ and $\mathrm{h}$ ). Although the deletion of Atrip amino acids 112-225 resulted in decreased stability of the protein, ${ }^{31}$ the association of Atrip $\Delta 112-225$ with Bid is decreased. As the Bid-Atrip association was preserved in deletions involving the TopBP1 domain, but not in deletions involving amino acids 112-225, the above data are most consistent with an association of Bid with the Atrip coiled-coil domain. Cells harboring Atrip/ $\Delta 112-225$ mutant showed defects in Chk1 phosphorylation and Atrip nuclear foci following replicative stress. $^{31}$

Bid helix 4 mutants maintain cell death activity. BidH4A and BidH4B maintain a comparable ability to bind to Bcl-2 and $\mathrm{Mcl}-1$, as well as the ability to be cleaved by caspase 8 (Figures $5 \mathrm{a}$ and $\mathrm{c}$ ). We further tested the ability of these helix 4 mutants to induce cell death by stably introducing Bid $+/+$ and BidH4A and H4B into U2OS cells. SiRNA KD of endogenous Bid but not control $\mathrm{KD}$ resulted in protection from TRAIL/cycloheximide-induced cell death. Trail-induced cell death was restored by re-introduction of $\mathrm{Bid}+/+$ or $\mathrm{BidH} 4 \mathrm{~A}$ and BidH4B but not Bid mutated in the $\mathrm{BH} 3$ domain (Figure $5 \mathrm{~d}$ ). HU treatment induced minimal cell death in U2OS cells. Expression of $\mathrm{Bid}+/+$ as well as $\mathrm{BidH} 4 \mathrm{~A}$ and BidH4B increased cell death following $\mathrm{HU}$ to a similar extent (Supplementary Figure S6C). Thus, Bid helix 4 mutants are able to be cleaved by caspases and to induce cell death following death receptor stimulation or $\mathrm{HU}$ treatment, providing further evidence that the structure and cell death function of Bid helix 4 mutants is intact (Figures $5 \mathrm{a}$ and $\mathrm{d}$ and data not shown). Furthermore, the two functions of Bid, cell death and DNA damage can be structurally separated, providing additional evidence that the DNA damage and apoptotic functions of Bid are distinct.

Bid helix 4 mediates the Atr-directed DNA damage response. To further define the role of Bid helix 4 in the Atr-directed DNA damage response, we reintroduced $\mathrm{BidH} 4 \mathrm{~A}$ or BidH4B into Bid KD U2OS cells, and evaluated $\mathrm{HU}$-induced accumulation of Atrip at nuclear foci, Chk1 phosphorylation, DNA damage, and recovery and completion of DNA replication. Bid helix 4 mutants failed to restore $\mathrm{HU}$-induced accumulation of Atrip at DNA damage foci (Figures 6a and b) or Chk1 phosphorylation in Bid KD U2OS cells (Figure 6c). To assess DNA damage following replicative stress, we performed alkaline Comet assays following $\mathrm{HU}$ treatment. Bid KD U2OS cells demonstrated increased DNA 
a

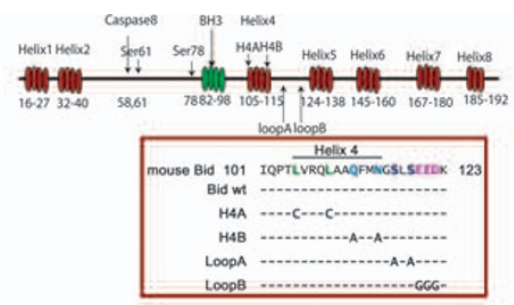

c
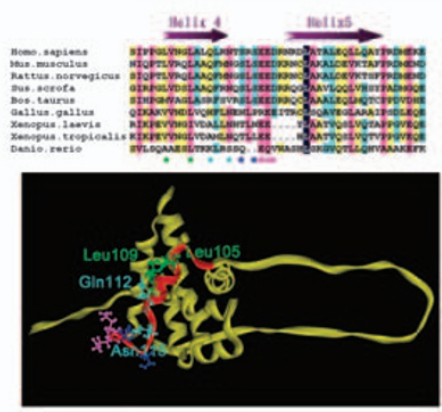

e

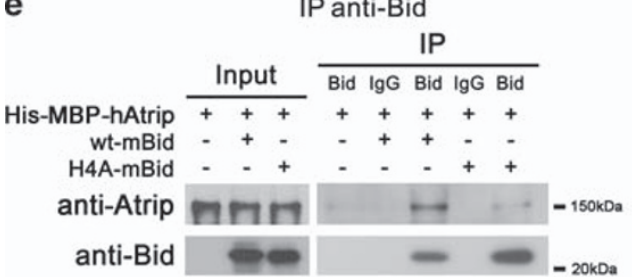

h

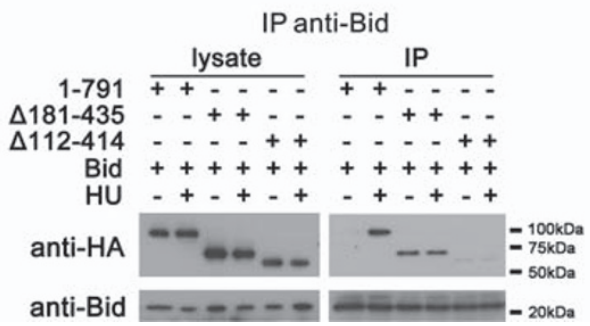

b

IP anti-Bid

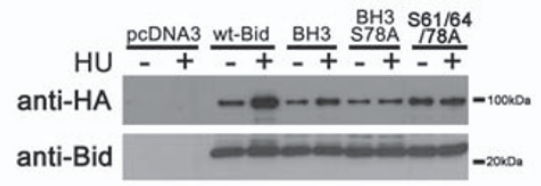

d

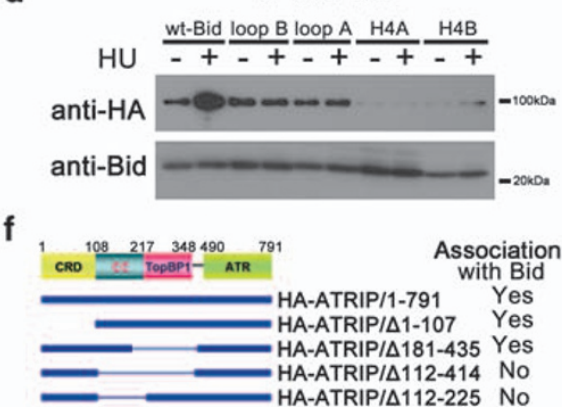

g

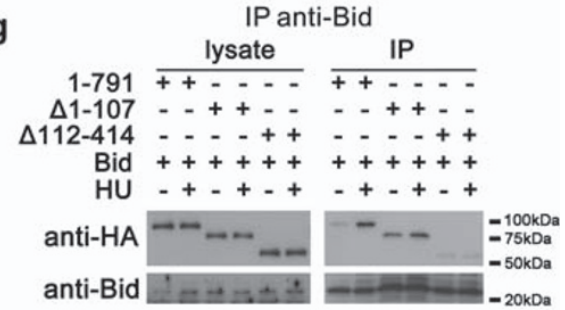

i

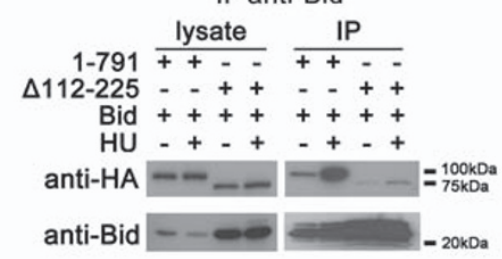

Figure 4 The helix 4 domain of Bid interacts with the coiled-coil domain of Atrip. (a) Schematic illustration of mouse Bid structure. (b) Cells (293T) were co-transfected with HA-Atrip/pLPCX, and either wild-type Bid, or Bid mutated in the BH3 domain or Bid mutated in the Atm/Atr consensus phosphorylation sites. Bid was immunoprecipitated from whole-cell extracts using anti-Bid antibody. Samples were resolved on SDS-PAGE followed by immunoblotting with the indicated antibodies. (c) Sequence alignment of the helix 4 and helix 5 of Bid among different species. Helix 4 and helix 5 are labeled as purple arrows. The GenBank accession numbers of the sequences used here are: Homo sapiens (NM_197966), Mus musculus (NM_007544), Rattus norvegicus (NM_022684), Gallus gallus (NM_204552), Danio rerio (NM_001079826), Sus scrofa (NM_001030535), Xenopus laevis (NM_001095594), Xenopus tropicalis (NM_001097226), and Bos taurus (NM_001075446). The alignment was performed by Clustal X. The Leu105 and Leu109 in helix 4 are labeled as green stars. The Gln112 and Asn115 in helix are labeled as cyan stars. Loop A amino acids are dark blue, Loop B amino acids are pink. The same amino acids are labeled in the nuclear magnetic resonance structure of Bid. ${ }^{30} \mathrm{Helix} 4$ is denoted in red, and is on an exposed surface of Bid. The BH3 domain is facing out of the page. (d) Cells (293T) were co-transfected with HA-Atrip/pLPCX, and wild-type Bid or Bid harboring mutations in helix 4: mutation of green stars to polar cysteine residues $(\mathrm{H} 4 \mathrm{~A})$, or of cyan stars to alanine residues $(\mathrm{H} 4 \mathrm{~B})$, or of dark blue stars at the end of helix 4 to alanine residues (loop $\mathrm{A}$ ), or of pink stars in the loop region between helices 4 and 5 to glycine (loop B) Bid was immunoprecipitated from whole-cell extracts and samples were analyzed as above. (e) Wild-type or helix 4-mutated Bid and His-MBP-Atrip protein were purified from E.coli. Bid (10 $\mu \mathrm{g})$ and $100 \mu \mathrm{g}$ His-MBP-Atrip protein were incubated in binding buffer at room temperature for $30 \mathrm{~min}$. Bid was immunoprecipitated using anti-Bid antibody, and the immunoprecipitated proteins were resolved on SDS-PAGE and immunoblotted with the indicated antibodies. (f) Schematic illustration of Atrip structure. CRD, checkpoint recruitment domain. CC, coiled-coil domain. TopBP1, TopBP1-interacting domain. ATR, Atr-binding domain. (g-i) Wild-type Bid and HA-tagged full-length or various truncated Atrip constructs were overexpressed in human 293T cells. Then the cells were treated with $10 \mathrm{mM} \mathrm{HU}$ for $2 \mathrm{~h}$ and Bid was immunoprecipitated by anti-Bid antibody. The immunoprecipitated products were detected by anti-Bid and anti-HA antibodies

damage relative to control $\mathrm{KD}$ cells as measured by tail moment. Expression of Bid $+/+$ but not BidH4A or BidH4B in Bid KD U2OS cells restored DNA damage levels to those observed in control KD cells. (Figure $6 \mathrm{~d}$ ). In addition, Bid +/+ but not BidH4A or BidH4B rescued the recovery and completion of DNA replication in Bid-deficient U2OS cells following $\mathrm{HU}$ (Figures $6 \mathrm{e}$ and f). Taken together, these results are consistent with a role for Bid in Atr activation, mediated by an interaction of Bid helix 4 with Atrip.

The RPA/Atr/Atrip association is decreased in the absence of Bid. To determine whether Bid alters the association of Atr/Atrip and RPA, we immunoprecipitated RPA70 or Atr from nuclear extracts of $\mathrm{HU}$-treated $\mathrm{Bid}+\mathrm{I}+$ 
a
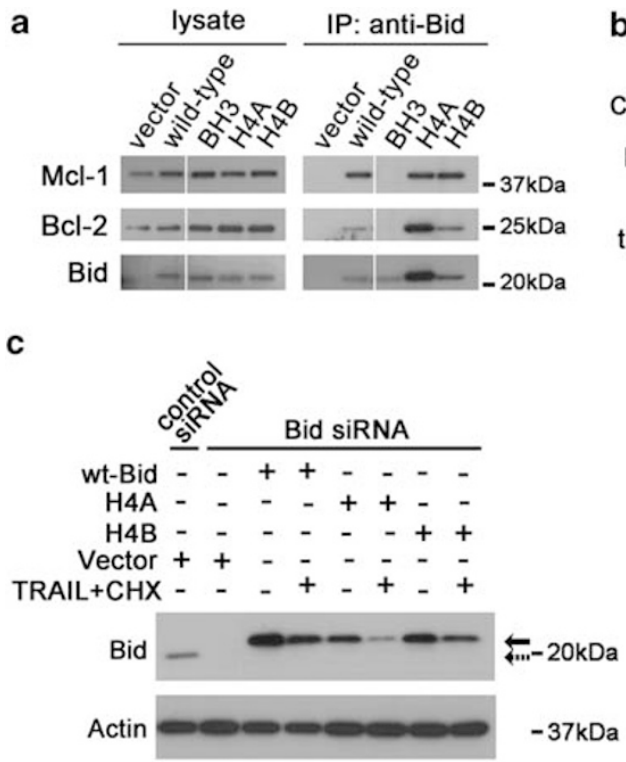

b
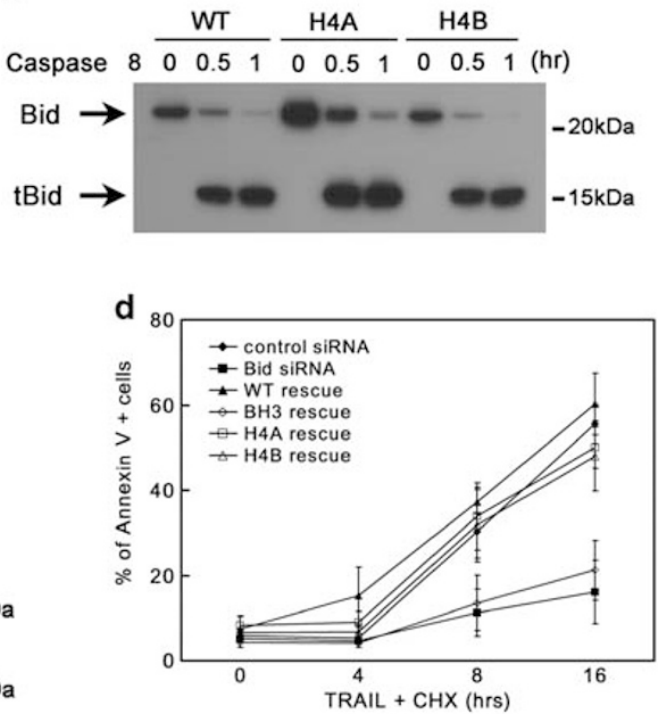

Figure 5 Mutations in helix 4 domain of Bid do not significantly change the function of Bid in the extrinsic cell death pathway. (a) Helix 4 mutated Bid binds with other Bcl-2 family proteins. Cells (293T) were transfected with wild-type Bid or helix 4-mutated Bid. Bid was immunoprecipitated from whole-cell extracts. Immunoprecipitates were resolved by SDS-PAGE followed by immunoblotting with anti-Bid, anti-Bcl-2 and anti-Mcl-1 antibodies. All the samples were run in the same gel with interrupted lanes deleted. (b) Helix 4-mutated Bid show similar sensitivity as wild-type Bid to caspase 8. Purified wild-type and two helix 4 Bid mutants (H4A and H4B) were cleaved by active caspase 8 (Millipore) in vitro for 0.5 and $1 \mathrm{~h}$. The full-length and truncated Bid in reaction products were analyzed by anti-Bid antibody in immunoblots. (c) U2OS cells overexpressing HAtagged wild-type or helix 4-mutated Bid was transfected with Bid siRNA for $72 \mathrm{~h}$. Silent mutations were introduced in the Bid siRNA-target region so that only endogenous Bid was knocked down by Bid siRNA. Then, cells were treated with $50 \mathrm{ng} / \mathrm{ml}$ TRAlL and $5 \mu \mathrm{g} / \mathrm{ml}$ cycloheximide (CHX) for $4 \mathrm{~h}$. Total cell lysate was analyzed by SDS-PAGE followed by immunoblotting with anti-Bid antibody. Solid and dashed arrows denote endogenous Bid and overexpressed Bid, respectively. (d) Cells harboring helix 4-mutated Bid show similar sensitivity to TRAIL/CHX treatment. U2OS cells overexpressing HA-tagged wild-type or various Bid mutations was transfected with Bid siRNA for $72 \mathrm{~h}$. Then, cells were treated with $50 \mathrm{ng} / \mathrm{ml}$ TRAIL and $5 \mu \mathrm{g} / \mathrm{ml} \mathrm{CHX} \mathrm{over} \mathrm{time.} \mathrm{The} \mathrm{apoptotic} \mathrm{cells} \mathrm{were} \mathrm{detected} \mathrm{by} \mathrm{Annexin} \mathrm{V-FITC} \mathrm{Apoptosis} \mathrm{Detection} \mathrm{Kit} \mathrm{(BioVision,} \mathrm{Mountain} \mathrm{View,}$ CA, USA)

and Bid-/- MPCs. The association of Atr/Atrip and RPA was decreased in the absence of Bid (Figure 7a). In addition, there was a trend toward decreased RPA foci in the absence of Bid (Supplementary Figure S6D and E). Taken together, our data are most consistent with a role for Bid to facilitate Atr signaling through modulating the DNA damage sensor complex.

\section{Discussion}

The BH3-only Bcl-2 family members serve as sensors for cellular damage, transducing death signals to the multidomain family members at the mitochondria. These proapoptotic $\mathrm{BH} 3-$ only proteins may function by participating in fundamental cellular processes, ${ }^{2,17,32,33}$ in position to sense potentially catastrophic perturbations in cell function and signal to the core apoptotic machinery. Bid has been shown to be a substrate of Atm/Atr and loss of Bid results in an aberrant S-phase response to DNA damage. ${ }^{2,17}$

In this study, we demonstrate that Bid functions at a remarkably proximal position in the Atr-mediated DNA damage response to replicative stress, associating with Atr, Atrip, and RPA, in the DNA damage sensor complex. In our study, Bid-deficient cells exhibit several phenotypes consistent with limited Atr function following replicative stress: (1) Bid-/- cells are hypersensitive to replicative stress in vitro, ex vivo ${ }^{2}$ and in vivo (Figure $1 \mathrm{~b}$ ); (2) cell cycle re-entry ability is limited in Bid-deficient cells following $\mathrm{HU}$ withdrawal (Figure 1c); (3) chromatin-bound Atr and Atrip are significantly decreased following treatment with $\mathrm{HU}$ (Figure 1e); (4) activation of the Atr substrates Chk1 and RPA is decreased (Figure 2); and (5) the association of Atr/Atrip and RPA is diminished in the absence of Bid (Figure 7a). The data presented above clearly place Bid in the DNA damage response at the level of the sensor complex, and are consistent with a role for Bid in stabilization of the Atr/Atrip DNA damage sensor complex at nuclear foci following replicative stress, potentially by acting as a bridging protein. Alternatively, Bid may have a role in the stabilization of the replication fork after DNA damage.

Cells respond to stalled replication fork progression by activating signal transduction pathways to initiate a complex set of responses, including checkpoint activation, DNA repair, and in settings of irreparable DNA damage, programmed cell death or apoptosis. ${ }^{8}$ A multiprotein complex assembles in a highly coordinated and regulated manner at the site of the DNA lesion. RPA senses the accumulation of single-stranded DNA at stalled replication forks, and has a central role in checkpoint activation through interaction with Atrip to recruit Atr to the site of the DNA lesion. A unified model for activation of Atr/Atrip incorporating the current data in the literature on the role of the association with RPA-ssDNA has not yet developed. Atr-Atrip bound to RPA-coated single stranded DNA is not sufficient for checkpoint activation, but requires the ordered recruitment of additional factors, including the 9-1-1 complex and TopBP1 for downstream signaling to effect the complex response to DNA damage. ${ }^{34,35}$ This study places Bid, a member of the Bcl-2 family, in association with key 
a
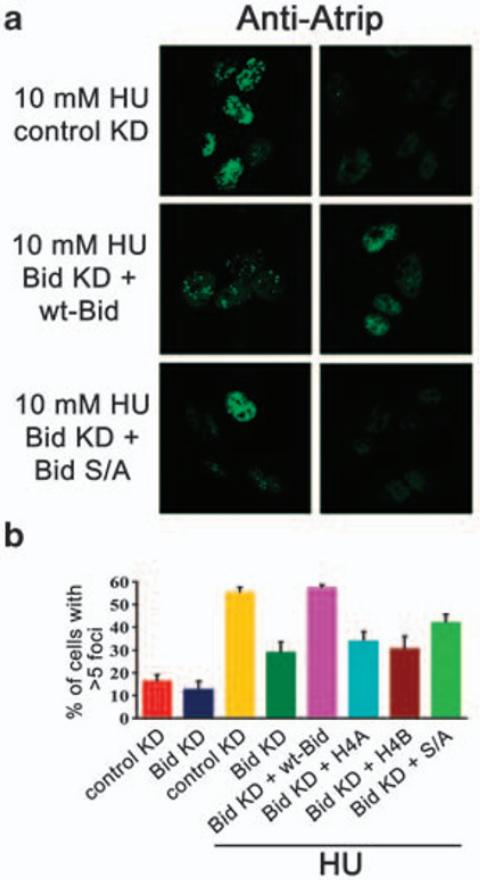

$10 \mathrm{mM} \mathrm{HU}$

Bid KD

$10 \mathrm{mM} \mathrm{HU}$

Bid KD +

Bid H4A

$10 \mathrm{mM} \mathrm{HU}$

Bid KD +

Bid H4B

d
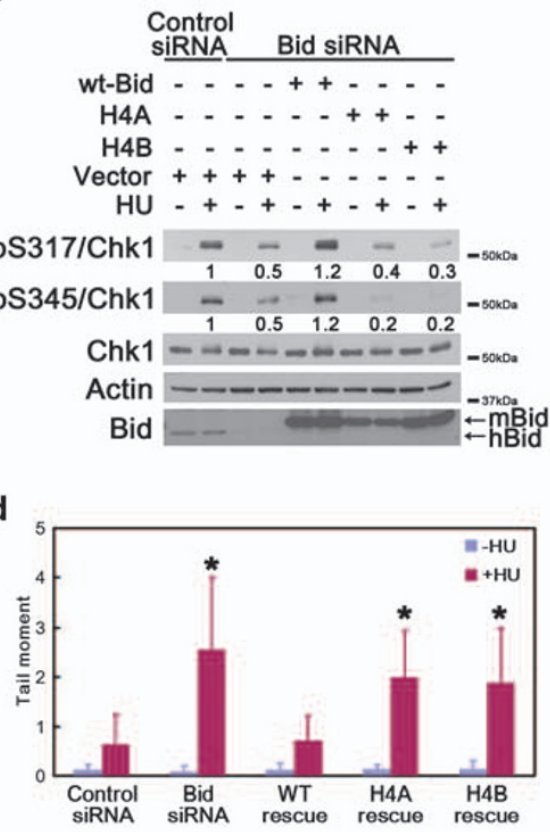

Bid

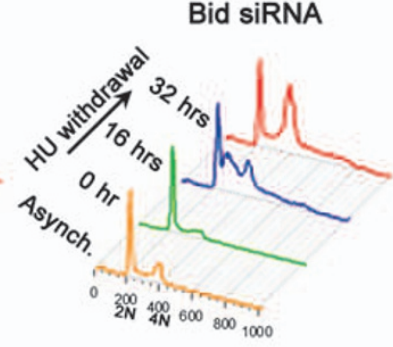

Bid-H4B

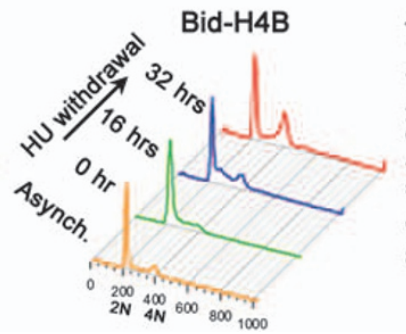

b control siRNA
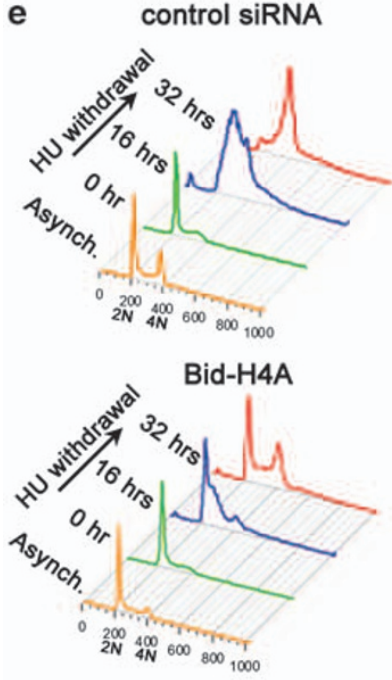

e

Figure 6 An intact Bid helix 4 is required for Bid's function following HU treatment. (a) U2OS cells transfected with control siRNA or Bid siRNA, and Bid KD cells with rescue by wt-Bid, H4A, H4B or phospho-mutated (S/A) Bid were treated with $10 \mathrm{mM} \mathrm{HU}$ for $5 \mathrm{~h}$, fixed, and stained with anti-Atrip antibody. Representative images of Atrip staining were shown. (b) Quantitative analysis of Atrip accumulation at nuclear foci following replicative stress. The percentage of cells with $>5$ clearly visible Atrip nuclear foci was calculated for each cell type. More than 600 cells were counted in three independent experiments. (c) U2OS cells were treated with control siRNA or Bid siRNA for $72 \mathrm{~h}$. Wild-type mouse Bid, Bid H4A, Bid H4B, or vector alone was introduced into the cells simultaneously with siRNA. Cells were treated with $10 \mathrm{mM} \mathrm{HU}$ for $2 \mathrm{~h}$. Total cell lysate was resolved on SDS-PAGE and immunoblotted as above. Relative band intensity of pChk1 signal has been measured by densitometry analysis. (d) U2OS cells overexpressing HA-tagged wild-type or helix 4-mutated hBid was transfected with Bid siRNA for $72 \mathrm{~h}$. Silent mutations were introduced in the Bid siRNA-target region so that only endogenous Bid was knocked down by Bid siRNA. Then, cells were treated with HU overnight. The untreated and treated cells were collected in ice-cold PBS and detected in alkaline comet assay. At least 60 randomly chosen comets/sample were analyzed by CometScore Program Version 1.5. ${ }^{*} P<0.05$. (e) U2OS cells overexpressing HA-tagged wild-type or helix 4-mutated hBid was transfected with Bid siRNA for $72 \mathrm{~h}$. Silent mutations were introduced in the Bid siRNA-target region so that only endogenous Bid was knocked down by Bid siRNA. Then, cells were treated with $\mathrm{HU}$ for overnight and released into fresh media containing $1 \mu \mathrm{g} / \mathrm{ml}$ nocodazole for the indicated times. Cells were fixed and stained with propidium iodide. Live cells were gated on FSC/SSC and analyzed by flow cytometry. The quantitative analysis of the arrested G1/early S phase cells following $32 \mathrm{~h} \mathrm{HU}$ withdrawal was shown in (f). ${ }^{*} P<0.05$. (f) The quantitative analysis of the arrested G1/early S-phase cells following HU withdrawal in Figure 6 e. Data were collected from three independent experiments. ${ }^{*} P<0.05$

proteins of the sensor complex. We further demonstrate that Bid has a role in the stable association of Atr/Atrip and RPA, and in an efficient Atr-mediated DNA damage response following replicative stress.
Following genotoxic stress, Atm/Atr phosphorylate Bid at Ser61 and Ser78. ${ }^{2}$ in this study, we found that mutation in Ser61/64/78 attenuates the induction of the Bid-Atrip interaction following $\mathrm{HU}$, but does not abrogate the interaction (Figure 4b). 
a
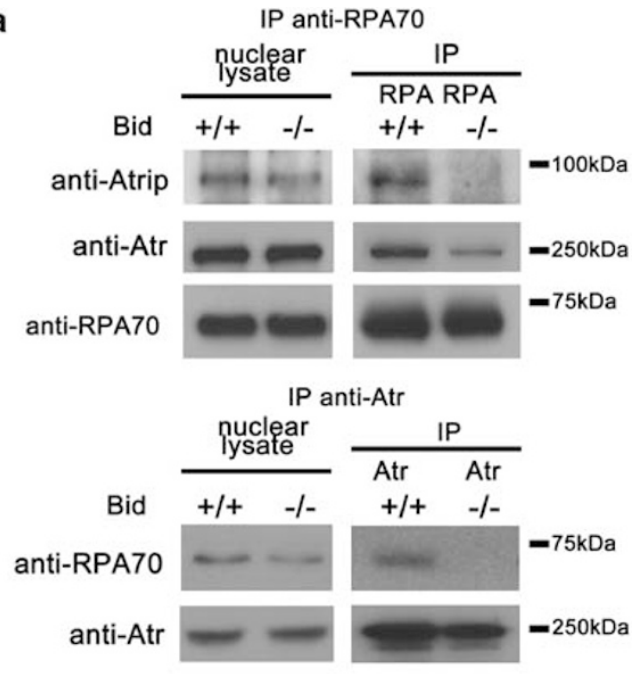

b replicative stress

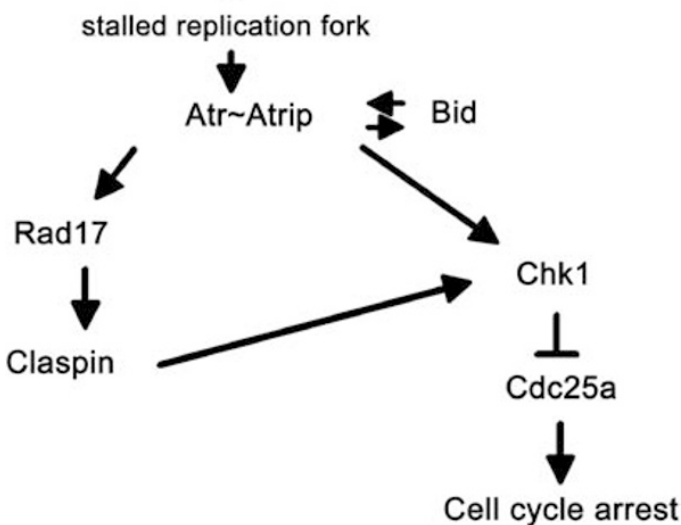

Figure 7 A proposed model for Bid in the Atr-mediated DNA damage response to replicative stress. (a) The damage complex is unstable in Bid-/- MPCs following $\mathrm{HU}$ treatment. Bid $+/+$ and Bid-/- MPCs were treated with $10 \mathrm{mM} \mathrm{HU}$ for $2 \mathrm{~h}$. Then, the nuclear fraction was purified and RPA or Atr was immunoprecipitated from nuclear extracts. The immunoprecipitated samples were analyzed using SDS-PAGE followed by immunoblotting with the indicated antibodies. (b) Schematic model of a proposed role for Bid in the Atr-mediated DNA damage signaling pathway. Bid serves as a mediator in the Atr-directed response to replicative stress at the level of Atr/Atrip activation. Bid associates with the Atr/Atrip complex via Atrip. Thus, Bid functions at the level of the sensor complex, to facilitate and amplify Atr-directed Chk1 activation and ensure rapid and efficient checkpoint activation

In addition, reintroduction of BidS61/64/78A only partially rescues the defects of Atrip nuclear foci in Bid KD U2OS cells (Figures 6a and $b$ ). Further investigation is required to clarify the detailed mechanism of Bid phosphorylation in the DNA damage response.

Recently, Mcl-1 has been demonstrated to be a novel mediator in the Atr-Chk1 pathway ${ }^{36,37}$ Although the Mcl-1 level is not significantly altered in Bid-deficient cells (Supplementary Figure S2B and C), the increased IP of BidH4A with no corresponding increase in the amount of co-immunoprecipitated Mcl-1 (Figure 5a), suggests that binding of Mcl-1 to BidH4A (but not BidH4B) might be reduced. Additional experiments will be required to evaluate the potential interaction of Bid and Mcl-1 in the DNA damage response.
Our initial results differ from results reported by Kaufmann et al. ${ }^{19}$ with respect to the magnitude of sensitivity of Bid-/cells to replicative stress. ${ }^{2,38}$ Kaufmann et al. used different cell types and activation stimuli, thus the experiments are not directly comparable. Cells vary significantly in their apoptotic response to DNA damage, by both cell lineage as well as differentiation state due both to the percentage of cycling cells as well as the 'hardwiring' of the cell. Immature, rapidly cycling hematopoietic cells showing a high propensity to undergo apoptosis. Fibroblasts are substantially more resistant. Moreover, redundancy in the apoptotic pathway, particularly with respect to the role of a given $\mathrm{BH} 3-$ only protein, results in variability of apoptotic outcome by cell signal and cell type. We expect that the differences observed between our group and Kaufmann et al. were because of the cells and experimental parameters used. This is consistent with an effect that is cell type or context specific as we have proposed.

Distinct from cells defective in other classic mediators/ effectors, such as Atrip, Rad17, and Claspin, the Chk1 activation process is in fact initiated, albeit to a lesser extent, in Bid-/- cells following DNA damage treatment. Moreover, Bid-/- mice develop normally, whereas mice lacking the essential mediators/effectors (Atr, Chk1, Rad17) die early in embryonic development. The normal developmental program in the absence of Bid may reflect the presence of redundancy or tissue/developmental stage specificity to the role of Bid in Atr signaling. Bid is present at high levels in hematopoietic cells, Bid-/- bone marrow is sensitive to in vivo $\mathrm{HU}$, and Bid-/- mice develop CMML, ${ }^{39}$ consistent with a role for Bid in hematopoietic homeostasis and leukemogenesis. Although it is interesting to speculate that the location of Bid as a participant in the DNA damage sensor complex places, it in position to have a key role in determining the fate of a cell following DNA damage, further studies will be necessary to dissect the roles of Bid's apoptotic versus DNA damage function in this setting.

\section{Materials and Methods}

Cell lines and drug treatments. Hox11-immortalized Bid $+1+$ and Bid-1MPCs ${ }^{6,17}$ were cultured in IMDM medium (Invitrogen, Carlsbad, CA, USA) with $20 \%$ FBS, $100 \mathrm{U} / \mathrm{ml}$ penicillin-streptomycin, $2 \mathrm{mM}$ glutamine, $0.1 \mathrm{mM} \beta$-mercaptoethanol, and $10 \%$ conditioned medium from WEHI cells as a source of IL-3. U2OS cells, Bid-/- MEFs harboring HA-tagged Bid, were cultured in DMEM (Invitrogen) with $10 \% \mathrm{FBS}, 100 \mathrm{U} / \mathrm{ml}$ penicillin-streptomycin, $2 \mathrm{mM}$ glutamine, and $0.1 \mathrm{mM}$ $\beta$-mercaptoethanol. Early passage cells $(10<P<20)$ were treated with $\mathrm{HU}$ (Sigma, St. Louis, MO, USA) or ETOP (Sigma) as indicated.

RNAi treatment and overexpression. The siRNA oligonucleotides targeting human Bid (SI02661911, SI02662415) were purchased from Qiagen Inc. (Valencia, CA, USA). The no. 7 (SI02661911) and no. 8 (SI02662415) hBid siRNA target sequence are $5^{\prime}$-AAAGACAATGTTAAACTTATA-3' and $5^{\prime}$-CAGGGA TGAGTGCATCACAAA $-3^{\prime}$, respectively. For U2OS cells, the transfection of Bid siRNA and control siRNA (1027310, target sequence: $5^{\prime}$-AATTCTCCGAACGTGTC ACGT-3') was mediated by Lipofectamine 2000 (Invitrogen) according to the manufacturer's instructions. Without specific mention, no.7 and no.8 hBid siRNA was mixed together and used as Bid siRNA in experiments. After $72 \mathrm{~h}$ transfection, the transfected U2OS cells were treated as indicated in the figure legends. For overexpression, siRNA and various Bid constructs in pcDNA3 vector were cotransfected into U2OS cells by Lipofectamine 2000 (Invitrogen) according to the manufacturer's instructions. After $72 \mathrm{~h}$ transfection, the cells were treated with $10 \mathrm{mM} \mathrm{HU}$ for $2 \mathrm{~h}$. 
Immunofluorescence staining. For Atrip nuclear foci, Bid siRNA, or control siRNA was delivered into U2OS cells by Lipofectamine 2000. After $40 \mathrm{~h}$ pcDNA3 vector containing wild-type mouse Bid or $\mathrm{H} 4 \mathrm{~A}$ mutant Bid or vector alone was introduced by FuGene 6 (Roche, Nutley, NJ, USA). After another $40 \mathrm{~h}$, the cells were treated with $10 \mathrm{mM} \mathrm{HU}$ for $5 \mathrm{~h}$. Then, the cells were fixed by $3 \%$ paraformaldehyde/2\% sucrose solution and permeabilized by Triton $\mathrm{X}-100$ solution (0.5\% Triton X-100, $20 \mathrm{mM}$ HEPES pH7.4, $50 \mathrm{mM} \mathrm{NaCl}, 3 \mathrm{mM} \mathrm{MgCl}, 300 \mathrm{mM}$ sucrose). Atrip localization was detected by immunofluorescence using anti-Atrip polyclonal antibody $403 .{ }^{9}$ The cells were examined using a Leica DM IRBE inverted wild-field microscope (Bannockburn, IL, USA).

For Bid-RPA co-localization analysis, synchronized Bid-/- MEFs harboring HA-tagged Bid were fixed in cold 3:1 methanol:acetone and blocked for $1 \mathrm{~h}$ with $5 \%$ Normal Goat Serum (Sigma) in PBS. RPA was detected by immunofluorescence using Rat anti-RPA32 antibody (Cell Signaling, Danvers, MA, USA) and Alexa Fluor 546 conjugated Goat anti-Rat IgG antibody (Invitrogen). HA-tagged Bid was detected by immunofluorescence using Alexa Fluor 488 conjugated mouse anti-HA IgG (Invitrogen). Microscopy was performed using a Zeiss (Thornwood, NY, USA) LSM 510 inverted confocal microscope.

IP. For endogenous IP, the chromatin-enriched nuclear fractions of Bid $+/+$ MPCs or U2OS cells were collected and lysed in lysis buffer (25 mM HEPES pH 7.5 $250 \mathrm{~mm} \mathrm{NaCl}, 2 \mathrm{mM}$ EDTA, $10 \%$ glycerol, $0.5 \%$ NP-40, $1 \mathrm{mM} \mathrm{PMSF}, 4 \mu \mathrm{g} / \mathrm{ml}$ leupeptin/antipain, $0.1 \mathrm{mM}$ orthovanadate, $1 \mathrm{mM} \mathrm{NaF}$ ). Then, biotinylated antihuman/mouse Bid goat polyclonal antibody (R\&D Systems, Minneapolis, MN, USA, BAF860), anti-Atrip 403, ${ }^{9}$ anti-RPA70 (US biological, R3400), control IgG (Santa Cruz, Santa Cruz, CA, USA), was added to the lysate, and incubated at $4^{\circ} \mathrm{C}$ for $1 \mathrm{~h}$ as indicated in the figure legends. Streptavidin agarose (Novagen, Gibbstown, NJ, USA), TrueBlot anti-Rabbit Ig IP Beads (cat no. 00-8800, eBioscience Inc., San Diego, CA, USA) or TrueBlot anti-mouse Ig IP Beads (cat no. 00-8811, eBioscience Inc.) were added and samples were incubated at $4{ }^{\circ} \mathrm{C}$ for $2 \mathrm{~h}$. The beads were pelleted, washed, boiled with $5 \times$ Laemmli buffer and the supernatant was resolved on SDS-PAGE. For domain mapping experiments, the indicated Bid constructs in pcDNA3 vectors and the indicated HA-tagged Atrip constructs in pLPCX vector (from Dr. David Cortez) were transfected using Lipofectamine (Invitrogen) and expressed in $293 \mathrm{~T}$ cells for $48 \mathrm{~h}$. Total cell lysates were prepared and IP was performed as indicated in the figure legend.

Protein purification and in vitro interaction. The E. coli BL21 strains harboring Atrip/pSV282 (a generous gift from Dr. David Cortez) were induced by $0.1 \mathrm{mM}$ isopropyl- $\beta$-D-thiogalactopyranoside (IPTG) at room temperature for $8 \mathrm{~h}$ and the His-MBP-Atrip fusion protein was purified as previous described, ${ }^{40}$ widetype or mutated mouse Bid cDNA was cloned into pGEX-6P-1 vectors and induced in BL21 strains by $1 \mathrm{mM} \mathrm{IPTG}$ at $37^{\circ} \mathrm{C}$ for $4 \mathrm{~h}$. The harvested cells were resuspended in lysis buffer $(50 \mathrm{mM}$ Tris- $\mathrm{HCl}, 50 \mathrm{mM} \mathrm{NaCl}, 5 \mathrm{mM}$ EDTA, $1 \%$ Triton $\mathrm{X}-100,1 \mathrm{mM}$ DTT, $1 \mathrm{mM}$ PMSF, pH 8.0) and centrifugated at $20000 \mathrm{~g}$ for $20 \mathrm{~min}$ at $4{ }^{\circ} \mathrm{C}$ After incubation with glutathione-agarose for $3 \mathrm{~h}$ at $4{ }^{\circ} \mathrm{C}$ the supernatant was discarded and the beads were incubated with prescission protease (GE Healthcare Bioscience, Piscataway, $\mathrm{NJ}$, USA) at $4{ }^{\circ} \mathrm{C}$ overnight. The Bid protein in the supernatant was dialyzed in $30 \mathrm{mM}$ Tris- $\mathrm{HCl}(\mathrm{pH} 8.0)$.

For the Bid-Atrip in vitro interaction, $10 \mu \mathrm{g}$ Bid and $100 \mu \mathrm{g}$ His-MBP-Atrip protein were incubated in binding buffer ( $20 \mathrm{mM} \mathrm{HEPES}, 100 \mathrm{mM} \mathrm{KCl}, 5 \mathrm{mM} \mathrm{MgCl}$ $0.5 \mathrm{mM}$ EDTA, $0.1 \% \mathrm{NP}-40, \mathrm{pH} 7.5$ ) at room temperature for $30 \mathrm{~min}$. Then biotinylated anti-human/mouse Bid goat polyclonal antibody (R\&D Systems, BAF860) was added and incubated at $4^{\circ} \mathrm{C}$ for $1 \mathrm{~h}$. Streptavidin agarose (Novagen) was then added and incubated at $4{ }^{\circ} \mathrm{C}$ for $2 \mathrm{~h}$. The beads were pelleted by centrifugation and washed four times with binding buffer. The beads were boiled with $5 \times$ Laemmli buffer and the supernatant was subjected to SDS-PAGE.

Chk1 IP-kinase assay. U2OS cells transfected with control siRNA or Bid siRNA (no. 8) for $72 \mathrm{~h}$ were treated with $10 \mathrm{mM} \mathrm{HU}$ for $2 \mathrm{~h}$. The cells were lysed in IP buffer (25 mM HEPES, $250 \mathrm{mM} \mathrm{NaCl}, 2 \mathrm{mM}$ EDTA, $0.5 \mathrm{NP}-40,10 \%$ glycerol, $4 \mu \mathrm{g} / \mathrm{ml}$ leupeptin/antipain, $1 \mathrm{mM}$ PMSF, $10 \mathrm{mM} \beta$-glycerophosphate, $0.1 \mathrm{mM}$ orthovanadate, $1 \mathrm{mM} \mathrm{NaF}, \mathrm{pH} 7.5)$ and Chk1 was immunoprecipitated using polyclonal anti-Chk1 antibody (Chemicon, Temecula, CA, USA, AB3539) and protein $\mathrm{G}$ sepharose (Invitrogen). The immunoprecipitated products were washed once with kinase buffer ( $10 \mathrm{mM}$ HEPES, $50 \mathrm{mM} \mathrm{NaCl}, 50 \mathrm{mM} \beta$-glycerophosphate, $10 \mathrm{mM} \mathrm{MgCl}_{2}, 10 \mathrm{MnCl}_{2}, 1 \mathrm{mM} \mathrm{DTT}, \mathrm{pH}$ 7.5) and incubated with $1 \mu \mathrm{g} \mathrm{GST-Cdc25C}$ protein (a generous gift from Dr. Jennifer Pietenpol) on ice for $5 \mathrm{~min}$. Then, $10 \mu \mathrm{M}$ cold ATP and $5 \mu \mathrm{Ci}$ were added to the reaction. The kinase reactions were performed at room temperature for $1 \mathrm{~h}$ and stopped by adding $5 \times$ Laemmli buffer. Kinase reactions were resolved on SDS-PAGE. Gels were stained with SimplyBlue SafeStain (Invitrogen) according to the manufacturer's instructions, photographed, and dried before the autoradiography.

Subcellular fractionation. Subcellular fractionation of MPCs or U2OS cells were performed as previously described ${ }^{41}$ with minor modification. In brief, $10 \times 10^{6}$ MPCs were washed once with PBS and suspended in $400 \mu \mathrm{l}$ solution A (10 mM HEPES pH7.9, $10 \mathrm{mM} \mathrm{KCl}, 1.5 \mathrm{mM} \mathrm{MgCl}_{2}, 0.34 \mathrm{M}$ sucrose, $10 \%$ glycerol, $1 \mathrm{mM}$ DTT, $1 \mathrm{mM}$ PMSF, $10 \mathrm{mM} \mathrm{NaF}, 10 \mathrm{mM} \beta$-glycerophosphate, $1 \mu \mathrm{M}$ microcystin) with $0.1 \% \mathrm{NP}-40$ on ice for $5 \mathrm{~min}$. The cytoplasmic and nuclear fractions were collected by centrifugation at $1300 \times g$ for 4 min at $4{ }^{\circ} \mathrm{C}$ The isolated nuclei were washed once with solution $A$ and then lysed in solution $B$ ( 3 mM EDTA, $0.2 \mathrm{mM}$ EGTA, $1 \mathrm{mM}$ DTT, $1 \mathrm{mM}$ PMSF, $10 \mathrm{mM} \mathrm{NaF}, 10 \mathrm{mM} \beta$-glycerophosphate, $1 \mu \mathrm{M}$ microcystin). After incubation on ice for $10 \mathrm{~min}$, chromatin fractions were harvested by centrifugation at $1700 \times g$ for 4 min at $4{ }^{\circ} \mathrm{C}$. The chromatin pellet was washed once with solution B and resuspended in $100 \mu \mathrm{l}$ RIPA buffer. After sonication for $20 \mathrm{~s}$, the samples were boiled with $5 \times$ Laemmli buffer.

Single-cell gel electrophoresis (Comet) assay. U2OS cells overexpressing HA-tagged wild-type or helix 4-mutated hBid was transfected with Bid siRNA for $72 \mathrm{~h}$. Silent mutations were introduced in the Bid siRNA-target region so that only endogenous Bid was knocked down by Bid siRNA. Then, cells were treated with $\mathrm{HU}$ overnight. The untreated and treated cells were collected in ice-cold PBS and alkaline Comet assay was performed by CometAssay Kit (Trevigen, Gaithersburg, MD, USA). Briefly, cells were mixed with molten LMAgarose and pipetted onto CometSlide. After incubation with Lysis Solution and Alkaline Solution, slides were placed in Genemate Compact Gel tank (Bioexpress, Kaysville, UT, USA) and TBE electrophoresis was performed at $22 \mathrm{~V}$ for $10 \mathrm{~min}$. After incubation with $70 \%$ ethanol for $5 \mathrm{~min}$, the slides were stained with SYBR green I. Then, samples were examined using a Leica DM IRBE inverted wild-field microscope and analyzed by CometScore Program Version 1.5 .

Antibodies. The following antibodies were used in this study: anti-Bid rabbit polyclonal antibody, ${ }^{42}$ anti-Bid polyclonal antibody (R\&D Systems, BAF860), antiBid polyclonal antibody (Santa Cruz, FL-195), anti-Chk1 monoclonal antibody (Santa Cruz, G-4), anti-phospho-Chk1 (S345) polyclonal antibody (Cell signaling, 2341), anti-phospho-Chk1 (S317) polyclonal antibody (Cell signaling, 2344), antiCdc25A monoclonal antibody (Santa Cruz, F6), anti-Bax polyclonal antibody, ${ }^{43}$ antiActin monoclonal antibody (Sigma), anti-histone $\mathrm{H} 3$ monoclonal antibody (Upstate Biotechnology, Waltham, MA, USA, 05-928), anti-I $\kappa$ B polyclonal antibody (Cell signaling, 9242), anti-p53 monoclonal antibody (Santa Cruz, Pab240), antiphospho-p53(S15) polyclonal antibody (Cell signaling, 9284), anti-HA monoclonal antibody (Roche, 12CA5), and anti-Atrip polyclonal antibody (403; Cortez et al. ${ }^{9}$ ), anti-Atr polyclonal antibody (Santa Cruz, N-19), anti-RPA32 monoclonal antibody (Cell signaling, 2208), anti-RPA70 monoclonal antibody (US biological, R3400), anti-Mcl-1 polyclonal antibody (Rockland, Gilbertsville, PA, USA), anti-Bcl-2 monoclonal antibody (Pharmingen, San Diego, CA, USA), anti-RUNX1 antibody was a generous gift from Professor Hiebert.

\section{Conflicts of Interest}

The authors declare no conflict of interest.

Acknowledgements. We thank Dr. Jennifer Pietenpol, Dr. Scott Hiebert, Dr. David Cortez, Dr. Christine Eischen, Dr. Elizabeth Yang, Dr. Ellen Fanning, and Dr. Mark Boothby for many helpful discussions. We thank Dr. David Cortez for antiAtrip antibody and Atr/Atrip cDNA. This work was supported by funds from the Sidney Kimmel Foundation, the G\&P Foundation, ACS IRG-58-009-47, NIH K08 CA098394, and R01 HL088347 to SSZ. Cell imaging experiments were performed in the VUMC Cell Imaging Shared Resource.

1. Kamer I, Sarig R, Zaltsman Y, Niv H, Oberkovitz G, Regev L et al. Proapoptotic BID is an ATM effector in the DNA-damage response. Cell 2005; 122: 593-603.

2. Zinkel SS, Hurov KE, Ong C, Abtahi FM, Gross A, Korsmeyer SJ. A role for proapoptotic $\mathrm{BID}$ in the DNA-damage response. Cell 2005; 122: 579-591. 
3. Yin XM, Wang K, Gross A, Zhao Y, Zinkel S, Klocke B et al. Bid-deficient mice are resistant to Fas-induced hepatocellular apoptosis. Nature 1999; 400: 886-891.

4. Li H, Zhu H, Xu CJ, Yuan J. Cleavage of BID by caspase 8 mediates the mitochondrial damage in the Fas pathway of apoptosis. Cell 1998; 94: 491-501.

5. Luo X, Budihardjo I, Zou H, Slaughter C, Wang X. Bid, a Bcl2 interacting protein, mediates cytochrome $\mathrm{c}$ release from mitochondria in response to activation of cell surface death receptors. Cell 1998; 94: 481-490.

6. Zinkel SS, Ong CC, Ferguson DO, Iwasaki H, Akashi K, Bronson RT et al. Proapoptotic BID is required for myeloid homeostasis and tumor suppression. Genes Dev 2003; 17: 229-239.

7. Matsuoka S, Ballif BA, Smogorzewska A, McDonald iii ER, Hurov KE, Luo J et al. ATM and ATR substrate analysis reveals extensive protein networks responsive to DNA damage. Science 2007; 316: 1160-1166.

8. Sancar A, Lindsey-Boltz LA, Unsal-Kacmaz K, Linn S. Molecular mechanisms of mammalian DNA repair and the DNA damage checkpoints. Annu Rev Biochem 2004; 73: 39-85

9. Cortez D, Guntuku S, Qin J, Elledge SJ. ATR and ATRIP: partners in checkpoint signaling Science 2001; 294: 1713-1716.

10. Falck J, Coates J, Jackson SP. Conserved modes of recruitment of ATM, ATR and DNAPKcs to sites of DNA damage. Nature 2005; 434: 605-611.

11. Zou L, Elledge SJ. Sensing DNA damage through ATRIP recognition of RPA-ssDNA complexes. Science 2003; 300: 1542-1548.

12. Ball HL, Ehrhardt MR, Mordes DA, Glick GG, Chazin WJ, Cortez D. Function of a conserved checkpoint recruitment domain in ATRIP proteins. Mol Cell Biol 2007; 27: 3367-3377.

13. Bermudez VP, Lindsey-Boltz LA, Cesare AJ, Maniwa Y, Griffith JD, Hurwitz J et al. Loading of the human 9-1-1 checkpoint complex onto DNA by the checkpoint clamp loader hRad17replication factor C complex in vitro. Proc Natl Acad Sci USA 2003; 100: 1633-1638.

14. Zou L, Cortez D, Elledge SJ. Regulation of ATR substrate selection by Rad17-dependent loading of Rad9 complexes onto chromatin. Genes Dev 2002; 16: 198-208.

15. Delacroix S, Wagner JM, Kobayashi M, Yamamoto K, Karnitz LM. The Rad9-Hus1-Rad1 (9-1-1) clamp activates checkpoint signaling via TopBP1. Genes Dev 2007; 21: 1472-1477.

16. Mordes DA, Glick GG, Zhao R, Cortez D. TopBP1 activates ATR through ATRIP and PIKK regulatory domain. Genes Dev 2008; 22: 1478-1489.

17. Wang J, Iwasaki H, Krivtsov A, Febbo PG, Thorner AR, Ernst P et al. Conditional MLL-CBP targets GMP and models therapy-related myeloproliferative disease. EMBO J 2005; 24 368-381.

18. Stracker TH, Morales M, Couto SS, Hussein H, Petrini JH. The carboxy terminus of NBS1 is required for induction of apoptosis by the MRE11 complex. Nature 2007; 447: 218-221.

19. Kaufmann T, Tai L, Ekert PG, Huang DC, Norris F, Lindemann RK et al. The BH3-only protein bid is dispensable for DNA damage- and replicative stress-induced apoptosis or cell-cycle arrest. Cell 2007; 129: 423-433.

20. Myers K, Gagou ME, Zuazua-Villar P, Rodriguez R, Meuth M. ATR and Chk1 suppress a caspase-3-dependent apoptotic response following DNA replication stress. PLoS Genet 2009; 5: e1000324.

21. Sax JK, Fei P, Murphy ME, Bernhard E, Korsmeyer SJ, El-Deiry WS. BID regulation by p53 contributes to chemosensitivity. Nat Cell Biol 2002; 4: 842-849.

22. Casper AM, Nghiem P, Arlt MF, Glover TW. ATR regulates fragile site stability. Cell 2002 111: $779-789$
23. Shimuta K, Nakajo N, Uto K, Hayano Y, Okazaki K, Sagata N. Chk1 is activated transiently and targets Cdc25A for degradation at the Xenopus midblastula transition. EMBO J 2002 21: 3694-3703.

24. Xiao Z, Chen Z, Gunasekera AH, Sowin TJ, Rosenberg SH, Fesik S et al. Chk1 mediates S and $\mathrm{G} 2$ arrests through Cdc25A degradation in response to DNA-damaging agents. J Biol Chem 2003; 278: 21767-21773.

25. Shiloh Y. ATM and ATR: networking cellular responses to DNA damage. Curr Opin Genet Dev 2001; 11: 71-77.

26. Fisher D, Mechali M. Sleeping policemen for DNA replication? Nat Cell Biol 2004; 6 : 576-577.

27. Kastan MB, Bartek J. Cell-cycle checkpoints and cancer. Nature 2004; 432: 316-323.

28. Maya-Mendoza A, Petermann E, Gillespie DA, Caldecott KW, Jackson DA. Chk1 regulates the density of active replication origins during the vertebrate S phase. EMBO J 2007; 26 2719-2731.

29. Chou JJ, Li H, Salvesen GS, Yuan J, Wagner G. Solution structure of BID, an intracellular amplifier of apoptotic signaling. Cell 1999; 96: 615-624.

30. McDonnell JM, Fushman D, Milliman CL, Korsmeyer SJ, Cowburn D. Solution structure of the proapoptotic molecule BID: a structural basis for apoptotic agonists and antagonists. Cell 1999; 96: 625-634.

31. Ball HL, Cortez D. ATRIP oligomerization is required for ATR-dependent checkpoint signaling. J Biol Chem 2005; 280: 31390-31396.

32. Cheng WC, Berman SB, Ivanovska I, Jonas EA, Lee SJ, Chen Y et al. Mitochondrial factors with dual roles in death and survival. Oncogene 2006; 25: 4697-4705.

33. Danial NN, Walensky LD, Zhang CY, Choi CS, Fisher JK, Molina AJ et al. Dual role of proapoptotic BAD in insulin secretion and beta cell survival. Nat Med 2008; 14 144-153.

34. Burrows AE, Elledge SJ. How ATR turns on: TopBP1 goes on ATRIP with ATR. Genes Dev 2008; 22: 1416-1421.

35. Cimprich KA, Cortez D. ATR: an essential regulator of genome integrity. Nat Rev 2008; 9 616-627.

36. Jamil S, Mojtabavi S, Hojabrpour P, Cheah S, Duronio V. An essential role for MCL-1 in ATR-mediated CHK1 phosphorylation. Mol Biol Cell 2008; 19: 3212-3220.

37. Jamil S, Stoica C, Hackett TL, Duronio V. MCL-1 localizes to sites of DNA damage and regulates DNA damage response. Cell Cycle 2010; 9: 2843-2855.

38. Zinkel SS, Hurov KE, Gross A. Bid plays a role in the DNA damage response. Cell 2007 130: 9-10 author reply 10-11.

39. Olsson M, Vakifahmetoglu H, Abruzzo PM, Hogstrand K, Grandien A, Zhivotovsky B. DISC-mediated activation of caspase-2 in DNA damage-induced apoptosis. Oncogene 2009; 28: 1949-1959.

40. Liu Y, Zhao TJ, Yan YB, Zhou HM. Increase of soluble expression in Escherichia coli cytoplasm by a protein disulfide isomerase gene fusion system. Protein Expr Purif 2005 44: $155-161$.

41. Méndez J, Stillman B. Chromatin association of human origin recognition complex, cdc6, and minichromosome maintenance proteins during the cell cycle: assembly of prereplication complexes in late mitosis. Mol Cell Biol 2000; 20: 8602-8612.

42. Wang K, Yin XM, Chao DT, Milliman CL, Korsmeyer SJ. BID: a novel BH3 domain-only death agonist. Genes Dev 1996; 10: 2859-2869.

43. Xiang J, Chao DT, Korsmeyer SJ. BAX-induced cell death may not require interleukin 1 beta-converting enzyme-like proteases. Proc Natl Acad Sci USA 1996; 93 14559-14563. 